\title{
CHAPTER SEVEN
}

\section{The Processing of Negative Polarity ITEMS IN TURKISH-GERMAN BILINGUALS ${ }^{1}$}

\author{
SECKIN ARSLAN, SOL LAGO, \\ AYDOĞAN YANILMAZ, JOHN E. DRURY \\ AND CLAUDIA FELSER
}

This study investigates the processing of Turkish negative polarity items (NPIs) using a self-paced reading experiment with end-of-sentence acceptability judgements. Our participants included adult Turkish monolinguals, as well as Turkish-German early (i.e. heritage speakers) and late bilinguals. We explored whether intrusion effects from illusory NPI licensors extended to bilingual Turkish speakers who had acquired German either early or late in their lives. Stimuli included 30 sets of sentences in six experimental conditions, with the presence of both an NPI and of a suitable licenser (verb negation) systematically manipulated. Our results indicate that bilingual Turkish readers show intrusion effects in their processing of NPIs. Our findings suggest that the structural conditions for NPI licensing in Turkish might be degraded or less stable in heritage bilinguals.

\section{Introduction}

The current study investigates how monolingual and bilingual Turkish readers process negative polarity items (NPIs) during reading comprehension. Given previous research which has shown that monolingual speakers are susceptible to intrusion effects when comprehending NPIs (e.g., Drenhaus, Saddy, and Frisch 2005; Vasishth, Brüssow, Lewis, and Drenhaus 2008),

\footnotetext{
${ }^{1}$ We thank Ayşe Gürel, Bilal Kırkıcı, Semra Kizilkaya and Simge Sargın for their help during participant recruitment. This research was supported by an Alexandervon-Humboldt professorship awarded to Harald Clahsen.
} 
we examine whether similar intrusion effects arise in early and late bilingual speakers.

NPIs are a class of expressions such as English anybody or ever and Turkish kimse ("anybody") that must occur within the scope of a licensing element, the most prototypical of which is negation (Giannakidou 2011). Previous research on the processing of NPIs in monolingual speakers has shown that such dependencies are susceptible to intrusion effects, which are observed when a potential licensor occurs in a structurally illicit position: Compare No man [that the woman liked] ever arrived on time with *The man [that no woman liked] ever arrived on time. Whereas the NPI ever in the former sentence is within the scope of negation, this is not the case in the latter sentence, which can potentially give rise to intrusion effects.

Intrusion effects have been documented for languages such as English and German, where NPI licensing involves a retrospective dependency in that the licensors linearly precede NPIs (e.g., Drenhaus, Saddy, and Frisch 2005; Xiang, Dillon, and Phillips 2008; Parker and Phillips 2016). On the other hand, the corresponding dependency in Turkish has the opposite linear order, since NPIs linearly precede their licensors. Thus, unlike in English or German, NPI licensing in Turkish involves a prospective dependency. For example, as illustrated by (1), the NPI kimse "anybody" occurs before its licensor (the negation -mA suffix) ${ }^{2}$ and requires its presence to be well-formed (compare (1) with *Kimse uyudu "Nobody slept.").
(1) Kimse uyu-ma-d 1
Anybody sleep.NEG.PST
"Anybody did not sleep." = "Nobody slept."

In an earlier ERP study, Yanilmaz and Drury (2018) examined Turkish native speakers' processing of NPI licensing. Their study used sentences with embedded clauses to create suitable contexts for intrusive licensors, with the NPI kimse occurring as the subject of the matrix clause. ${ }^{3}$ In their paradigm (e.g. 2a-c), the presence of negation on the matrix verb in (2a) allows for proper NPI licensing, whilst its absence leads to an outright violation in (2c). In the ungrammatical condition $(2 b)$, the presence of negation on the embedded verb (2b) gave rise to intrusion effects.

\footnotetext{
2 Here we follow the convention in traditional Turkish linguistics where the capitalized vowel symbolizes the alternation of the harmonizing vowels.

${ }^{3}$ Note that their design also included conditions where the NPI occurred as the subject of the embedded clause.
} 
(2)
a. Kimse
[Ali’nin çalıştığını] anybody
[Ali.GEN work.OBJPART]
"Anybody did not say that Ali worked." = "Nobody said that..."
b. *Kimse
[Ali'nin çalış-ma-dığını] söyledi
anybody
[Ali.GEN work.NEG.OBJPART] say.PST
"Anybody said that Ali did not work."
c. *Kimse
[Ali’nin çalıştığını]
söyledi
anybody
[Ali.GEN work.OBJPART]
"Anybody said that Ali worked."
say.PST

söyle-me-di

Say.NEG.PST

The authors found that neither participants' brain responses nor their offline judgments in the intrusion condition $(2 \mathrm{~b})$ patterned with those of the violation condition (2c). In fact, the ERPs elicited by the intrusion condition (2b) resembled those of sentences in which NPIs were licenced locally by the embedded negation. As for the offline behavioural results, the intrusion condition was judged with intermediate accuracy and elicited longer response times as compared to the NPI violation (i.e. no-licensing) condition. In summary, Yanilmaz and Drury's (2018) study showed robust intrusion effects in a language which requires prospective dependency formation for NPI licensing.

The present study examined Turkish-German bilingual speakers' processing of sentences containing either licensed or unlicensed NPIs using a self-paced reading acceptability judgment task. We specifically investigated Turkish-German bilinguals for whom both retrospective (German) and prospective (Turkish) dependency formation should be available. We divided our participants into two groups: (i) a heritage group, who had acquired German as a societally dominant language early in life, alongside their family or home language (Turkish), and (ii) an L2 group, comprised of native Turkish speakers who had acquired German later in life as a second or foreign language.

With Turkish heritage speakers, our goal was to assess whether they were sensitive to NPI licensing requirements and/or susceptible to intrusion effects during processing. Given previous evidence that heritage speakers may show signs of attrition especially in domains that require the integration of different kinds of linguistic information (see Montrul 2012, for review), we might expect heritage speakers to show reduced sensitivity to NPI licensing in Turkish. Note that successful NPI licensing requires several steps and the integration of syntactic and semantic information: 
First, an NPI must be recognized as an element that requires licensing. In German, encountering an NPI should trigger a backward-looking search for a suitable licensor, whilst Turkish NPIs should trigger a forwardlooking (i.e. predictive) search. In each case, to identify a suitable licensor, a potential licensor's scope domain must be determined. This, in turn, requires the computation of sufficiently detailed hierarchical phrasestructure representations and sensitivity to c-command. It is conceivable that speakers who acquired their native language under reduced input/output conditions (henceforth, heritage language conditions) have difficulty performing one or more of these steps as quickly or as accurately as monolingual speakers. General problems with Turkish NPI licensing should be reflected in a reduced sensitivity to the presence of ungrammatical (unlicensed) NPIs. Problems computing scope domains (rather than insensitivity to NPI licencing requirements as such), on the other hand, should selectively increase their susceptibility to intrusion effects.

A group of L2 German speakers was included to allow us to assess whether knowledge of German had an effect on native Turkish speakers' sensitivity to NPI licensing even if German was acquired comparatively late. Participants also included a monolingual control group, for whom we expected to replicate the behavioral results reported by Yanilmaz and Drury (2018).

\section{Methods}

\subsection{Participants}

All participants were native Turkish speakers who were either Turkish monolinguals $(\mathrm{n}=37)$, Turkish-German heritage bilinguals $(\mathrm{n}=32)$ or German L2 speakers $(n=24)$. The monolingual participants lived in Turkey and reported little or no exposure to German (mean age $=27$ years, age range $=19-57,24$ females, 34 right-handed). The heritage speakers (mean age $=25$ years, age range $=17-46,20$ females, 30 right-handed) lived in Germany and had acquired German before puberty (mean $=4$ years; range $=0-13$ ). The L2 speakers (mean age $=28$ years, age range $=$ 21-54, 14 females, 17 right-handed) had all acquired German after puberty $($ mean $=22$ years; range $=14-32)$. The majority of L2 speakers resided in Germany $(n=18)$, with the remaining ones living in Turkey $(n=5)$ and Italy $(\mathrm{n}=1)$.

All bilingual participants were assessed in both their Turkish and German language skills with a self-rating questionnaire that asked them to 
evaluate their proficiency in each of the four competencies (speaking, listening, reading and writing) on a scale from 1-10. These ratings were then averaged and converted to percentages to obtain an overall measure of their language proficiency. The questionnaire results showed that the heritage speakers rated their Turkish proficiency at around $89 \%$ (range $=$ $65-100 \%$ ) and their German proficiency at around 95\% (range $=70$ $100 \%$ ). By contrast, the L2 group rated their Turkish proficiency at around $99 \%$ (range $=80-100 \%$ ) and their German proficiency at around $63 \%$ (range $=20-90 \%)$.

\subsection{Materials}

Our sentence stimuli were adapted from the materials used by Yanılmaz and Drury (2018). They included 30 item sets distributed across six conditions, which varied the presence of an NPI (absent/present) and the availability and position of the NEGATION licensor (main clause/embedded clause/no licensor). An item set with numbered regions is shown in (3):

(3a) No negation -NPI (critical condition, grammatical)

$\begin{array}{llllll}\mathbf{R 1} & \mathbf{R 2} & \mathbf{R 3} & \mathbf{R 4} & \mathbf{R 5} & \mathbf{R 6} \\ \text { Kemal } & \text { [RC Ali'nin } & \text { çalıştığın1] } & \text { söyledi } & \text { bana } & \text { bugün. } \\ \text { Kemal } & \text { Ali.GEN } & \text { work.OBJPART } & \text { say.PST } & \text { me.DAT } & \text { today. }\end{array}$

"Kemal told me that Ali worked today"

(3b) No negation +NPI (critical condition, ungrammatical)

$\begin{array}{llllll}\text { R1 } & \text { R2 } & \text { R3 } & \text { R4 } & \text { R5 } & \text { R6 }\end{array}$

Kimse [RC Ali'nin çalıştığını] söyledi bana bugün.

Anybody Ali.gen work.oBJPART say.PST me.DAT today.

"No one told me that Ali worked today"

(3c) Embedded verb negation -NPI (critical condition, grammatical)

$\begin{array}{llllll}\mathbf{R 1} & \mathbf{R 2} & \mathbf{R 3} & \mathbf{R 4} & \mathbf{R 5} & \mathbf{R 6} \\ \text { Kemal } & \text { [RC Ali'nin çalıșmadığın1] } & \text { söyledi } & \text { bana } & \text { bugün. } \\ \text { Kemal } & \text { Ali.GEN } & \text { work.NEG.OBJPART } & \text { say.PST } & \text { me.DAT } & \text { today. }\end{array}$

"Kemal told me that Ali did not work today" 
(3d) Embedded verb negation +NPI (critical condition, intrusion)

$\begin{array}{llllll}\text { R1 } & \text { R2 } & \text { R3 } & \text { R4 } & \text { R5 } & \text { R6 }\end{array}$

Kimse [RC Ali'nin çalıșmadığını] söyledi bana bugün.

Anybody Ali.gen work.NEG.obJPART say.PST me.DAT today.

"No one told me that Ali did not work today"

(3e) Main verb negation -NPI (control condition, grammatical)

\begin{tabular}{|c|c|c|c|c|c|}
\hline R1 & $\mathbf{R 2}$ & $\mathbf{R 3}$ & R4 & R5 & R6 \\
\hline Kemal & [RC Ali'nin & çalıştığını] & söylemedi & bana & bugün. \\
\hline Kemal & Ali.GEN & work.OBJPART & Say.NEG.PST & me.DAT & today. \\
\hline
\end{tabular}

(3f) Main verb negation +NPI (control condition, grammatical)

$\begin{array}{llllll}\mathbf{R 1} & \mathbf{R 2} & \mathbf{R 3} & \mathbf{R 4} & \mathbf{R 5} & \mathbf{R 6} \\ \text { Kimse } & \text { [RC Ali'nin } & \text { çalıştı̆̆ın1] } & \text { söylemedi } & \text { bana } & \text { bugün. } \\ \begin{array}{ll}\text { Anybody Ali.GEN } \\ \text { "No one did not tell me that Ali worked today" }\end{array} & \text { me.DAT } & \text { today. }\end{array}$

The critical conditions were $(3 a-d)$. The no-negation pair $(3 a, b)$ provided a baseline measure of participants' sensitivity to ungrammaticality due to containing an unlicensed NPI: If speakers apply NPI licensing constraints online, then sentences with an unlicensed NPI (and without an intrusive licensor) should elicit processing disruptions after the main verb in comparison to sentences without an NPI ( $3 \mathrm{~b}$ vs. $3 \mathrm{a}$ ).

The critical question was whether similar processing disruptions would be observed for sentences with an intrusive licensor, i.e. a negative particle on the embedded verb (intrusion pair $3 \mathrm{c}$,d). If speakers are susceptible to intrusion and sometimes erroneously link the NPI to a syntactically illicit licensor, then the processing cost reflecting ungrammaticality detection should be reduced in the intrusion pair $(3 \mathrm{c}, \mathrm{d})$ compared to the no-negation pair $(3 a, b)$. In other words, the presence of an unlicensed NPI should elicit smaller reading disruptions and more judgment errors (i.e. lower accuracy) in the intrusion than in the no-negation pair, resulting in a significant NPI $\times$ NEGATION interaction. Two further control conditions $(3 \mathrm{e}, \mathrm{f})$ were added to allow us to examine whether licensing an NPI incurred in processing cost even in the absence of any ungrammaticality.

Participants read sentences word-by-word and then provided end-ofsentence acceptability judgments. The experiment was run on the webbased platform Ibex Farm (Drummond 2013) using a self-paced noncumulative moving window design (Just, Carpenter, and Woolley 1982). The regions of interest consisted of the earliest region where the 
ungrammaticality of a sentence could be detected (R4: main verb region) and the following regions, which were identical across conditions. Byregion reading times were analyzed with linear mixed effects models (Baayen, Davidson, and Bates 2008) and judgment accuracies with mixed effects logistic regressions (Jaeger 2008). Reading times faster than 200 $\mathrm{ms}$ or slower than $5000 \mathrm{~ms}$ were excluded, and the remaining reading times were transformed for the statistical analysis based on the Box-Cox method (Box and Cox 1964), which suggested the reciprocal transformation for the monolingual and the L2 groups, and the log transformation for the heritage group. The three speaker groups (monolinguals/heritage/L2) were analyzed separately.

For the four critical conditions, the fixed effects structure of the model included main effects of NPI and NEGATION, as well as their interaction. The effects of interest were the main effect of NPI (which indicated whether speakers were sensitive to ungrammaticality) and the interaction NPI $\times$ NEGATION, which indicated whether speakers showed intrusion effects. The main effect of NEGATION was not of theoretical interest, as the critical conditions differed in the lexical frequency and length of the pretarget region (R3). However, this effect was included in the model to reflect the experimental design and account for the variance associated with this factor. All fixed effects were coded using sum contrasts. Significant interactions were followed-up with pairwise comparisons (reported in the text). The control conditions were analyzed separately. The structure of the random effects structure consisted of the maximal factor specification that converged (Barr, Levy, Scheepers, and Tily 2013). Unless indicated, this structure consisted of random intercepts and slopes for all fixed effects by participants and items. We report effect sizes using the model estimates $(\hat{E})$, standard errors $(S E)$ and $t$ - and $z$-statistics.

\section{Results}

We report the results for each participant group separately. The monolingual speakers demonstrated rapid sensitivity to ungrammaticality: ungrammatical sentences $(+\mathrm{NPI} ; 3 \mathrm{~b}, \mathrm{~d})$ elicited longer reading times than grammatical sentences (-NPI; 3a,c) immediately at the main verb. This pattern also appeared in the final sentence region, which critically showed a NPI $\times$ NEGATION interaction: The intrusion +NPI condition (3d) patterned closely together with the grammatical conditions in eliciting longer reading times, in contrast with the no-negation +NPI condition (3b), which showed faster reading times (Figure 7-1). Table 7-1 and Table 7-2 in the Appendix provide an overview of the results of the statistical analysis. 
As reading times in the final region are likely to partly reflect speakers' preparation for providing an end-of-sentence acceptability judgment, the elevated reading times in the intrusion condition suggest that monolinguals had more difficulty evaluating acceptability when the sentence contained an intrusive licensor than when it did not. Consistently, the pairwise comparisons revealed a stronger difference within the no-negation pair (3a vs. $3 \mathrm{~b} ; \hat{E}=-0.42 ; S E=0.08 ; t=-5.13 ; p=.000)$ than within the intrusion pair (3c vs. $3 \mathrm{~d} ; \hat{E}=-0.18 ; S E=0.10 ; t=-1.82 ; p=.077$ ). Further, intrusion also affected the monolingual speakers' acceptability judgments. As shown in Figure 7-2, the +NPI condition marginally decreased accuracy in the intrusion pair $(\hat{E}=-2.65 ; S E=1.51 ; z=-1.78 ; p=.078)$ but not in the no-negation pair $(\hat{E}=6.68 ; S E=5.52 ; z=1.21 ; p=.226)$. Finally, no effects were found in the control conditions in either reading times or judgments, suggesting that the licensing of an NPI, in the absence of ungrammaticality, did not elicit any additional processing cost. ${ }^{4,5}$

${ }^{4}$ Due to non-convergence, by-item slopes were removed in the analysis of accuracies and reading times. In the heritage group, by-item slopes were removed in the analysis of reading times at R6. In the L2 group, by-item slopes were removed in the analysis of accuracies.

${ }^{5}$ As shown in Table 7-1 and Table 7-2 in the Appendix, the groups sometimes showed main effects of NEGATION in reading times or judgments. These effects likely reflect the fact that the conditions with negated embedded verbs, which contained an additional negation, elicited more processing difficulty, causing overall longer reading times and lower accuracy than the no-negation conditions. Although interesting, these effects are independent of intrusion effects and they are likely related to the processing of negation more generally. Thus, they will not be discussed further. 
Figure 7-1. By-region reading-time averages for monolingual speakers

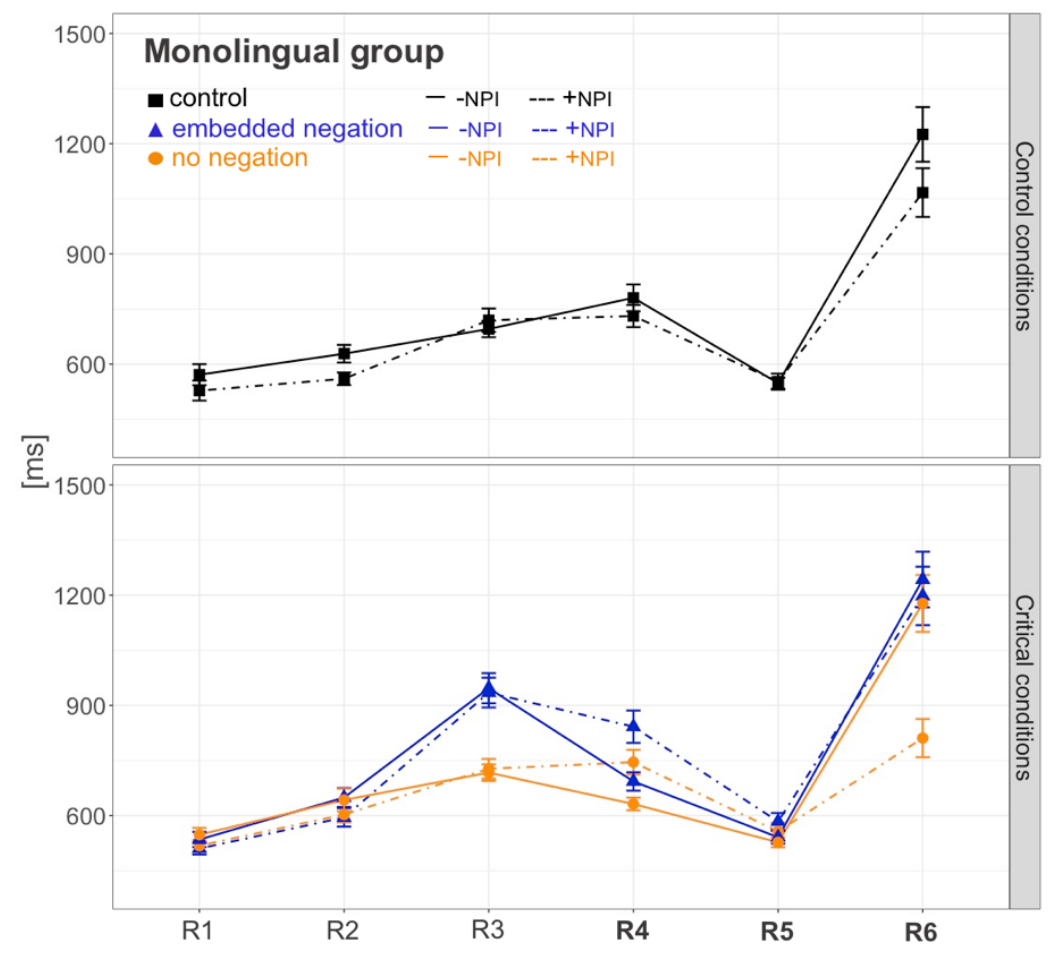

(Error bars indicate the standard error of the mean. Reading times are plotted in milliseconds for easier interpretability but they were transformed to account for non-normality prior to the statistical analysis. The regions of interest are bolded.) 
Figure 7-2. Mean acceptability judgment accuracy for the monolingual, heritage and $L 2$ groups

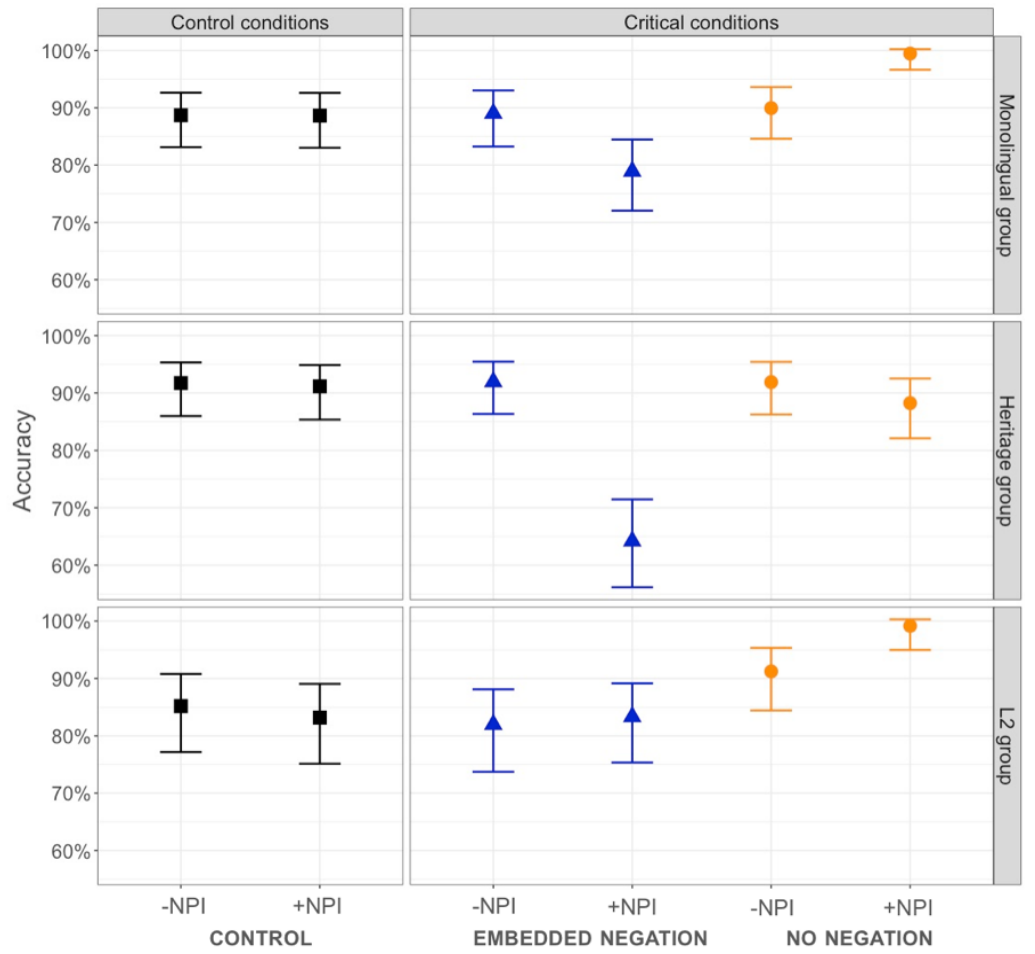

(Error bars indicate 95\% binomial confidence intervals. Accuracy is plotted in percentages for easier interpretability but it was transformed to log odds prior to the statistical analysis.)

The heritage group also showed immediate sensitivity to ungrammaticality at the main verb and following regions (Figure 7-3), as witnessed by significant main effect of the factor NPI. There was also some evidence of intrusion in the final region, with a marginal NPI $\times$ NEGATION interaction. Although the interaction was only marginally significant, we performed pairwise comparisons because they were motivated by our experimental hypotheses and in order to be consistent with the analysis of the monolingual group's data. These comparisons showed a marginal difference within the no-negation pair $(\hat{E}=-0.16 ; S E=0.09 ; t=-1.783 ; p$ $=.085)$ but not within the intrusion pair, in which the +NPI condition did not differ from its grammatical counterpart $(\hat{E}=0.02 ; S E=0.08 ; t=0.26$; 
$p=.793)$. There was clearer evidence of intrusion in the heritage speakers' judgment data: The +NPI condition showed decreased accuracy in the intrusion pair $(\hat{E}=-2.64 ; S E=1.09 ; z=-2.43 ; p=.015)$ but not in the nonegation pair $(\hat{E}=3.23 ; S E=2.43 ; t=1.33 ; p=.184)$. No effects were found in the control conditions.

\section{Figure 7-3. By-region reading-time averages for heritage speakers}

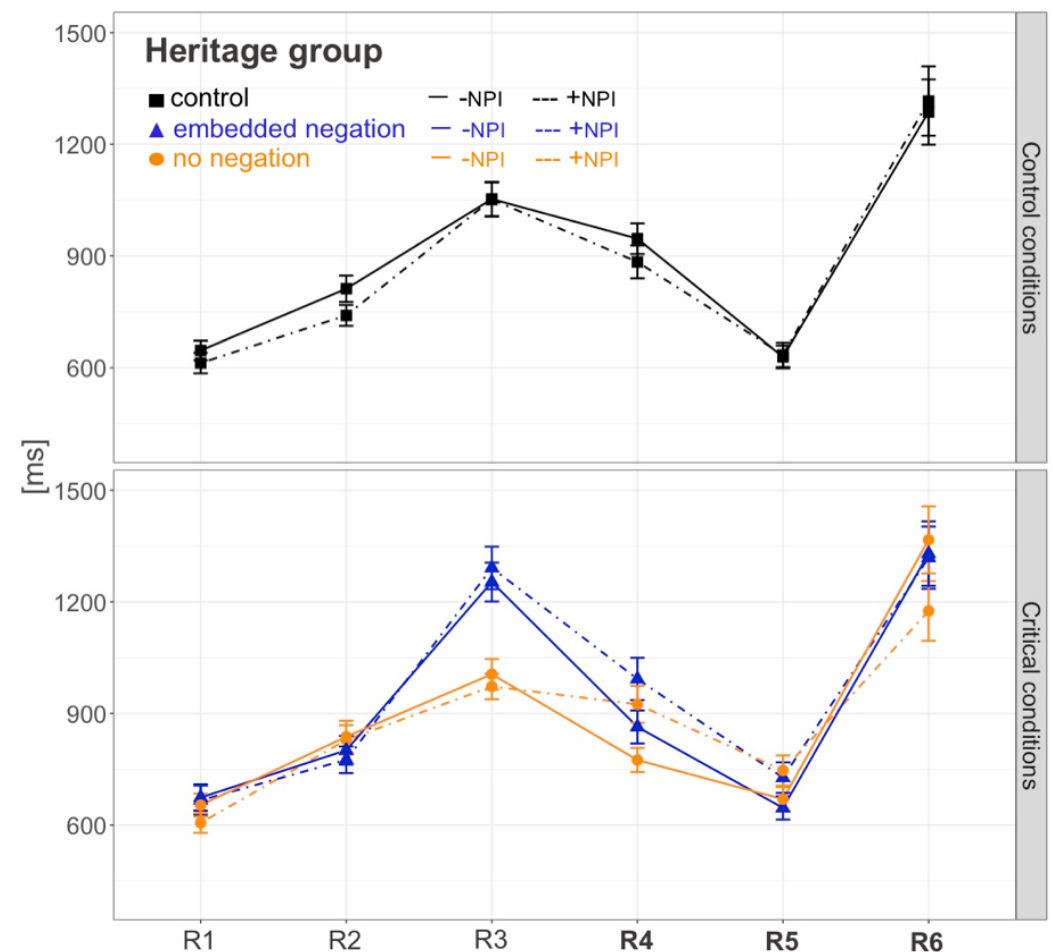

(Error bars indicate the standard error of the mean. Reading times are plotted in milliseconds for easier interpretability but they were transformed to account for non-normality prior to the statistical analysis. The regions of interest are bolded.)

Finally, the L2 group showed marginally slower reading times for ungrammatical conditions at the main verb and a significant grammaticality effect at the final sentence region (Figure 7-4). There was also evidence of intrusion in the final region, which showed a significant difference within the no-negation pair $(\hat{E}=-0.34 ; S E=0.09 ; t=-3.84 ; p=.000)$ but not within the intrusion pair $(\hat{E}=-0.10 ; S E=0.10 ; t=-1.05 ; p=.302)$. There 
was no evidence of intrusion in their judgment data and no effects in the control conditions.

Figure 7-4. By-region reading-time averages for $\mathrm{L} 2$ speakers

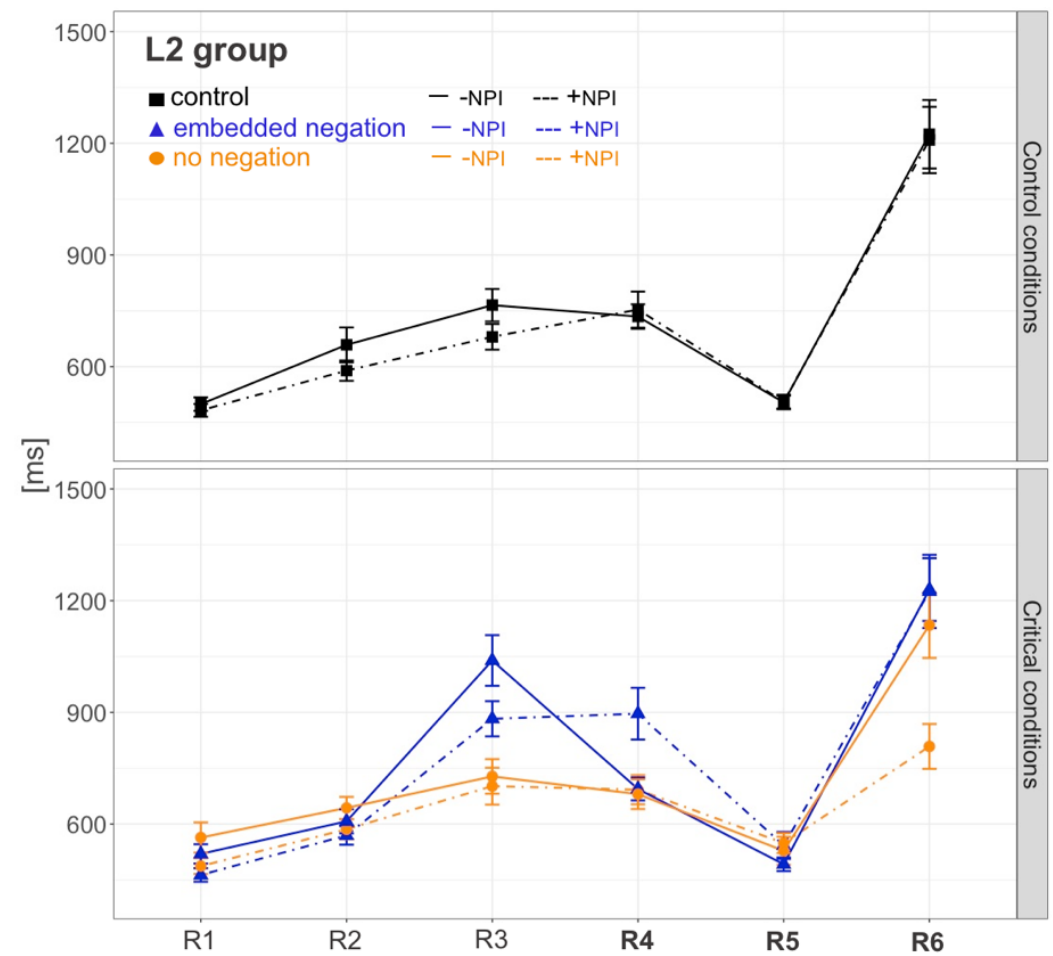

(Error bars indicate the standard error of the mean. Reading times are plotted in milliseconds for easier interpretability but they were transformed to account for non-normality prior to the statistical analysis. The regions of interest are bolded.)

\section{Discussion}

This study investigated whether Turkish monolinguals and TurkishGerman bilinguals were sensitive to NPI licensing requirements and intrusion effects during processing. We investigated this question in both early and late bilinguals, who varied in the age at which they had acquired German, a language that differs from Turkish in that NPIs have retrospective (rather than prospective) licensing constraints. 
Our findings show that all three groups of Turkish speakers were sensitive to ungrammatical sentences containing unlicensed NPIs, as evidenced by their slower reading times at the verb region for ungrammatical compared to grammatical sentences. This pattern suggests that like the monolingual group, bilingual participants were able to successfully detect unlicensed NPIs during online reading. Additionally, we found intrusion effects in the monolingual group's reading times at the sentence-final region, with a reduced ungrammaticality effect for the intrusion pair $(3 \mathrm{c}, \mathrm{d})$ compared to the grammatical vs. ungrammatical sentences which lacked a negation morpheme $(3 a, b)$. This is in line with the findings reported previously by Yanilmaz and Drury (2018).

Importantly, intrusion effects were also observed in the reading-time data of our heritage and L2 speakers. But in both cases the statistical marker of intrusion, the NPI $\times$ NEGATION interaction, was only marginal. We acknowledge this limitation, but we think that both the direction of the interaction and the similarity of the statistical patterns shown by our follow-up pairwise comparisons suggest that, like monolinguals, the heritage and L2 speakers showed evidence of intrusion. The marginal interactions are most likely due to reduced statistical power in the bilingual groups, which contained fewer speakers than the monolingual group and likely more variability, as reading data from bilingual speakers is typically more variable due to increased inter-individual differences. Although we attempted to reduce this variability by recruiting as many bilingual speakers as we could manage, it will be important to replicate these patterns in future work using larger samples.

The heritage speakers showed clear evidence of intrusion in their endof-trial judgments, more strongly than did the monolingual group. Both groups showed lower judgment accuracy for the intrusion condition compared to the other conditions, which indicates that they had difficulty rejecting ungrammatical sentences in the presence of an intrusive NPI licensor.

Taken together, our results confirm that Turkish-German bilingual speakers, including those who acquired Turkish under heritage language conditions, are sensitive to NPI licensing requirements but also show susceptibility to intrusion. Despite the observed similarities in our participants' behaviour, there were also some differences between the bilingual groups. Whereas L2 speakers showed intrusion effects in their reading times but not in their end-of-sentence judgments, the heritage group showed significant intrusion effects in their judgments, suggesting that the processing difficulties observed during the reading of the sentence persisted for longer in the heritage than the L2 group. 
The heritage group also showed lower judgment accuracy (64\%) than the other two groups in the intrusion condition (monolinguals: 79\%, L2 group: $83 \%$ ). This could be taken to indicate that monolingually raised Turkish speakers were more likely than heritage speakers to overcome the intrusion effect eventually, and to correctly identify sentences with intrusive licensors as ungrammatical. If this interpretation is on the right track, then these findings suggest that the structural conditions for NPI licensing in Turkish are less stable in heritage than in monolingually raised speakers. Although all our participant groups demonstrated sensitivity to the fact that NPIs require a licensor, distinguishing between suitable and unsuitable licensors by determining their scope domains may be more difficult for speakers who acquired Turkish under heritage language conditions.

The design of the present study does not allow us to determine whether the effects shown by the bilingual groups are due to influence from German, where NPI licensing involves the formation of a retrospective rather than of a prospective dependency, or whether NPI licensing (or more generally, scope relations) is a linguistic domain which is generally vulnerable to attrition or heritage language effects. Further research comparing bilingual speakers with different language combinations and examining potential effects of bilingualism onset more systematically will shed more light on these issues.

\section{References}

Baayen, R. Harald, Douglas J. Davidson, and Douglas M. Bates. 2008. "Mixed-effects Modeling with Crossed Random Effects for Subjects and Items." Journal of Memory and Language 59 (4): 390-412.

Barr, Dale J., Roger Levy, Christoph Scheepers, and Harry J. Tily. 2013. "Random Effects Structure for Confirmatory Hypothesis Testing: Keep it Maximal." Journal of Memory and Language 68 (3): 255-278.

Box, George EP., and David R. Cox. 1964. "An Analysis of Transformations." Journal of the Royal Statistical Society. Series B (Methodological) 26 (2): 211-252.

Drenhaus, Heiner, Douglas Saddy, and Stefan Frisch. 2005. "Processing Negative Polarity Items: When Negation Comes through the Backdoor." In Linguistic Evidence: Empirical, Theoretical, and Computational Perspectives, edited by Stephan Kepser, and Marga Reis, 145-165. Berlin: De Gruyter Mouton.

Drummond, Alex. 2013. "Ibex Farm." Online server: http://spellout. net/ibexfarm. 
Giannakidou, A. 2011. "Negative and Positive Polarity Items: Variation, Licensing, and Compositionality." In Semantics: An International Handbook of Natural Language Meaning, edited by Claudia Maienborn, Klaus von Heusinger, and Paul Portner, 1-45. Berlin: De Gruyter Mouton.

Jaeger, T. Florian. 2008. "Categorical Data Analysis: Away from ANOVAs (Transformation or not) and towards Logit Mixed Models." Journal of Memory and Language 59 (4): 434-446.

Just, Marcel A., Patricia A. Carpenter, and Jacqueline D. Woolley. 1982. "Paradigms and Processes in Reading Comprehension." Journal of Experimental Psychology: General 111 (2): 228.

Montrul, Silvina A. 2012. "Is the Heritage Language like a Second Language?" Eurosla Yearbook 12 (1): 1-29.

Parker, Dan, and Colin Phillips. 2016. "Negative Polarity Illusions and the Format of Hierarchical Encodings in Memory." Cognition 157: 321339.

Vasishth, Shravan, Sven Brüssow, Richard L. Lewis, and Heiner Drenhaus. 2008. "Processing Polarity: How the Ungrammatical Intrudes on the Grammatical." Cognitive Science 32 (4): 685-712.

Xiang, Ming, Brian Dillon, and Colin Phillips. 2009. "Illusory Licensing Effects across Dependency Types: ERP Evidence." Brain and Language 108 (1): 40-55.

Yanilmaz, Aydogan, and John E. Drury. 2018. "Prospective NPI Licensing and Intrusion in Turkish." Language, Cognition and Neuroscience 33 (1): 111-138. 
Table 7-1. Statistical results for reading times. (Model estimates $(\hat{E})$ are expressed in reciprocal (monolingual and L2 speakers) and $\log$ units (heritage speakers). Significant effects at the $\alpha=.05$ level are bolded, and marginal effects with $\alpha<.08$ are bolded and italicized.)

\begin{tabular}{|c|c|c|c|c|c|c|c|c|c|c|c|c|}
\hline & \multicolumn{12}{|c|}{ Reading times } \\
\hline & \multicolumn{4}{|c|}{$\mathrm{R} 4$} & \multicolumn{4}{|c|}{$\mathrm{R} 5$} & \multicolumn{4}{|c|}{ R6 } \\
\hline & $\hat{E}$ & $S E$ & $t$ & $p$ & $\hat{E}$ & $S E$ & $t$ & $p$ & $\hat{E}$ & $S E$ & $t$ & $p$ \\
\hline \multicolumn{13}{|l|}{ Monolingual speakers } \\
\hline NPI & 0.15 & 0.04 & 3.72 & .001 & -0.02 & 0.05 & -0.30 & .763 & -0.31 & 0.07 & -4.47 & .000 \\
\hline NEGATION & -0.09 & 0.04 & -2.55 & .013 & -0.03 & 0.05 & -0.67 & .509 & -0.25 & 0.06 & -4.07 & .000 \\
\hline NPI $\times$ NEGATION & 0.01 & 0.07 & 0.13 & .897 & -0.05 & 0.08 & -0.69 & .488 & -0.25 & 0.10 & -2.42 & .016 \\
\hline \multicolumn{13}{|l|}{ Heritage speakers } \\
\hline NPI & 0.11 & 0.04 & 2.81 & .008 & 0.07 & $\mathbf{0 . 0 3}$ & 2.29 & .036 & -0.06 & 0.06 & -0.96 & .343 \\
\hline NEGATION & -0.06 & 0.05 & -1.21 & .236 & 0.03 & 0.04 & 0.73 & .473 & -0.09 & 0.06 & -1.61 & .116 \\
\hline NPI $\times$ NEGATION & 0.04 & 0.06 & 0.61 & .544 & -0.01 & 0.06 & -0.20 & .840 & -0.19 & 0.10 & -1.96 & .051 \\
\hline \multicolumn{13}{|l|}{ L2 speakers } \\
\hline NPI & 0.11 & 0.06 & 1.85 & .080 & 0.08 & 0.07 & 1.18 & .251 & -0.23 & 0.07 & -3.32 & .002 \\
\hline NEGATION & -0.16 & 0.06 & -2.78 & .012 & 0.04 & 0.05 & 0.80 & .425 & -0.23 & 0.07 & -3.31 & .003 \\
\hline NPI $\times$ NEGATION & -0.08 & 0.09 & -0.86 & .392 & 0.07 & 0.09 & 0.76 & .450 & -0.23 & 0.12 & -1.89 & .060 \\
\hline
\end{tabular}


Table 7-2. Statistical results for judgement accuracy. (Estimates are expressed in $\log$ odds. Significant effects at the $\alpha=.05$ level are bolded, and marginal effects with $\alpha<.09$ are bolded and italicized.)

Judgment accuracy

\begin{tabular}{llll}
\hline$\hat{E}$ & $S E$ & $z$ & $p$ \\
\hline
\end{tabular}

Monolingual speakers

$\begin{array}{rllll}\text { NPI } & 0.54 & 1.08 & 0.50 & .615 \\ \text { NEGATION } & \mathbf{2 . 3 0} & \mathbf{0 . 6 9} & \mathbf{3 . 3 3} & \mathbf{. 0 0 1} \\ \text { NPI } \times \text { NEGATION } & \mathbf{5 . 4 9} & \mathbf{2 . 1 3} & \mathbf{2 . 5 8} & \mathbf{. 0 1 0}\end{array}$

Heritage speakers

$\begin{array}{rcccc}\text { NPI } & -0.86 & 0.73 & -1.18 & .238 \\ \text { NEGATION } & \mathbf{1 . 3 4} & \mathbf{0 . 4 9} & \mathbf{2 . 7 3} & \mathbf{. 0 0 6} \\ \text { NPI } \times \text { NEGATION } & \mathbf{2 . 3 1} & \mathbf{0 . 9 5} & \mathbf{2 . 4 4} & \mathbf{. 0 1 5}\end{array}$

L2 speakers

\begin{tabular}{rllll} 
NPI & 1.37 & 1.34 & 1.02 & .307 \\
NEGATION & $\mathbf{3 . 2 2}$ & $\mathbf{1 . 3 7}$ & $\mathbf{2 . 3 5}$ & $\mathbf{. 0 1 9}$ \\
NPI $\times$ NEGATION & 0.71 & 1.84 & 0.39 & .700 \\
\hline
\end{tabular}

